\title{
Sub-Micrometric MCM-41 Particles as Support to Design Efficient and Regenerable Maghemite-Based Sorbent for $\mathrm{H}_{2} \mathrm{~S}$ Removal
}

\author{
Claudio Cara ${ }^{1,2,3}$, Elisabetta Rombi ${ }^{1}$, Andrea Ardu ${ }^{1,2,3}$, Mirko Antonio Vacca ${ }^{1}$, and Carla Cannas ${ }^{1,2,3, *}$ \\ ${ }^{1}$ Department of Chemical and Geological Sciences, University of Cagliari, Monserrato (CA), 09042, Italy \\ ${ }^{2}$ Consorzio per la promozione di Attivitá Universitarie Sulcis-Iglesiente, Centro di Ricerca per l'Energia, \\ l'Ambiente e il TErritorio, Palazzo Bellavista Monteponi, Iglesias (Cl), 09016, Italy \\ ${ }^{3}$ Consorzio Interuniversitario Nazionale per la Scienza e Tecnologia dei Materiali (INSTM), \\ Cagliari Unit, Via Giuseppe Giusti, 9, 50121, Firenze, Italy
}

\begin{abstract}
In this work, highly dispersed maghemite $\left(\gamma-\mathrm{Fe}_{2} \mathrm{O}_{3}\right)$ in form of ultrasmall nanoparticles (about $2 \mathrm{~nm}$ ) was embedded into a mesostructured silica MCM-41 (about $600 \mathrm{~nm}$ ) featuring regular submicrometric hexagonal shaped particles via the two-solvent incipient wetness impregnation strategy. The obtained nanocomposite was then tested as $\mathrm{H}_{2} \mathrm{~S}$ sorbent in the mid-temperature range. When compared with a commercial sorbent (Katalko $\mathrm{JM}_{\mathrm{M}}$ 32-5), it showed superior performances after the first sulfidation which remained steady over three repeated sulfidation cycles, highlighting the regenerability properties of the composite. In order to evaluate the effect of the length of the pore channels on the accessibility of $\mathrm{H}_{2} \mathrm{~S}$ to the active phase, an analogous micrometric $\gamma-\mathrm{Fe}_{2} \mathrm{O}_{3} @ \mathrm{MCM}-41$, featuring micrometric channels and particles of irregular shape was used as reference.
\end{abstract}

Keywords: $\mathrm{H}_{2} \mathrm{~S}$ Removal, Sorbent, Mesostructured Silica, Maghemite.

\section{INTRODUCTION}

Iron oxides, due to their biocompatibility, non-toxicity, low cost, ${ }^{1}$ combined with their magnetic ${ }^{2}$ and semiconducting properties, have attracted great interest for several applications. ${ }^{3-6}$ Among them, maghemite $\left(\gamma-\mathrm{Fe}_{2} \mathrm{O}_{3}\right)$ with spinel structure, due to its ferrimagnetic properties and chemical stability, is widely used in different application fields, such as catalysis, ${ }^{7,8}$ biomedicine (magnetic resonance imaging (MRI), ${ }^{9}$ drug delivery, ${ }^{9,10}$ and magnetic fluid hyperthermia (MFH), ${ }^{11-13}$ gas sensor ${ }^{14,15}$ adsorption of liquid ${ }^{16,17}$ and gaseous pollutants. ${ }^{18}$ Concerning this latter application, $\mathrm{H}_{2} \mathrm{~S}$ removal from natural gas and sour syngas is of particular interest considering the large amounts produced and the harmful effects on the environment, and damages on pipes and turbines caused by corrosion phenomena in industrial plants. ${ }^{19-21}$ Among the several metal oxide-based candidates, although $\mathrm{ZnO}$ shows the most favorable thermodynamics, its main disadvantages such as the high regenerate temperature (at about $650{ }^{\circ} \mathrm{C}$, depending on particle dimension and atmosphere composition), ${ }^{19,21,22}$ and the moderate sulfur removal

\footnotetext{
*Author to whom correspondence should be addressed.
}

capacity per mass unit, ${ }^{22,27}$ render other oxides ${ }^{20,23,24}$ like maghemite appealing substitutes. ${ }^{18,25,26}$ In this context, maghemite has already proven itself to possess a remarkable ability to capture sulfur compounds, ${ }^{18}$ with specific affinity for $\mathrm{H}_{2} \mathrm{~S}$ in a natural gas $\left(\mathrm{CH}_{4}\right)$ atmosphere, ${ }^{27}$ due to the fast kinetics, the favorable thermodynamics of the reaction with $\mathrm{H}_{2} \mathrm{~S},{ }^{26,27}$ in a wide range of temperatures. $^{18,29}$ However, even though the sulfidation process can be performed in the range of low temperature $\left(<300{ }^{\circ} \mathrm{C}\right)$, avoiding in principle sintering or degradation phenomena of the sorbent, the regeneration process needs to be carried out above $350{ }^{\circ} \mathrm{C},{ }^{18,26}$ causing the gradual worsening in the sorbent's capacity. To overcome this issue, $\gamma-\mathrm{Fe}_{2} \mathrm{O}_{3}$ should be dispersed into a thermally stable support. ${ }^{25,26}$ Among the different supports, mesostructured silica shows ideal features to efficiently disperse the active phase. In fact, this strategy combines the distinctive features of mesostructured materials, such as high surface area and large accessibility owed to the regular dimension of the pores in the mesoporous range with the high $\mathrm{H}_{2} \mathrm{~S}$ removal capacity of maghemite, ${ }^{18,26}$ dispersed inside the pores in form of very small nanoparticles (with smaller dimension than the pore size). ${ }^{26}$ The performance 
of the sorbents are strictly related to the active phase as well as to the textural proprieties of the silica support. In this framework, different supports showing different dimension of the pores (MCM-41 vs. SBA-15), ${ }^{26}$ different silica particles dimension (from micrometric to nanometric particles), ${ }^{26}$ and different porous structure (hexagonal P6mm and cubic Ia3d $)^{25}$ were used to obtain the corresponding efficient and regenerable $\gamma-\mathrm{Fe}_{2} \mathrm{O}_{3} @ \mathrm{SiO}_{2}$ sorbents for $\mathrm{H}_{2} \mathrm{~S}$ removal. Even though ultrasmall maghemite nanoparticles were obtained after the impregnation route in all the proposed supports, it was demonstrated that the best performances over repeated sulfidation-regeneration cycles were achieved with MCM-41 with micrometric particles, due to the high stability of the support. Therefore, the higher accessibility to the active phase that would be theoretically achieved when the silica particles are in the nanometric range, was not observed due to the collapse of the porous structure. However, the increase in the silica particle size, from the nanometric to the sub-micrometric scale, would permit to combine the high accessibility of nanometric particles and the high porous structure stability of the micrometric ones. In this work, sub-microsized mesostructured silica particles with regular hexagonal shape were efficiently synthesized using ethyl acetate to regulate the size and shape on the particles, and efficiently impregnated to obtain the corresponding $\gamma-\mathrm{Fe}_{2} \mathrm{O}_{3} @ \mathrm{MCM}-41$ composite by means of the two-solvent impregnation strategy. The resulting material was then tested as a $\mathrm{H}_{2} \mathrm{~S}$ sorbent at $300{ }^{\circ} \mathrm{C}$ over three repeated sulfidation-regeneration cycles, and the performances compared to those of a commercial sorbent and an analogous $\gamma-\mathrm{Fe}_{2} \mathrm{O}_{3}$-based sorbent obtained from microsized MCM-41 particles, prepared in the absence of ethyl acetate. $^{26}$

\section{EXPERIMENTAL DETAILS}

\subsection{Chemicals}

All chemicals were of analytical grade and used as received without further purification. Hexadecyltrimethylammonium bromide (CTAB, 98\%), ethanol (azeotropic 95.6\%), ethyl acetate (EtOAc, 99.8\%), ammonium hydroxide $\left(\mathrm{NH}_{4} \mathrm{OH}, 28 \% \mathrm{NH}_{3}\right.$ in $\left.\mathrm{H}_{2} \mathrm{O}\right)$, tetraethyl orthosilicate (TEOS, 98\%), iron (III) nitrate nonahydrate (>99.5\%), $n$-hexane $(95 \%)$ were purchased from Sigma-Aldrich. Distilled water was used throughout the experiments.

\subsection{MCM-41 Support Preparation}

Sub-micrometric MCM-41 particles (MCM41_SM) were synthesized applying some modifications on the synthetic pathway presented in the reference articles. ${ }^{26}$ Specifically, $1 \mathrm{~g}$ of CTAB was dissolved in $300 \mathrm{ml}$ of distillate water and kept under mid stirring $(300 \mathrm{rpm})$ for 1 hour at $30^{\circ} \mathrm{C}$. Then, $30 \mathrm{ml}$ of $\mathrm{NH}_{4} \mathrm{OH}$ and $5 \mathrm{ml}$ of EtOAc were added and kept for 5 minutes under stirring. After that, the stirring rate was increased to $600 \mathrm{rpm}$ and $5 \mathrm{ml}$ of TEOS were injected all at once into the solution. The resulting milky dispersion was kept for 2 hours under mid stirring (300 rpm). The consequent separation was performed by centrifugation, and the obtained white powder was washed three times using a mixture 1:1 of water:ethanol. After drying at $80{ }^{\circ} \mathrm{C}$ overnight, calcination was carry out at $550{ }^{\circ} \mathrm{C}$ for 4 hours (heating rate $2{ }^{\circ} \mathrm{C} \mathrm{min}^{-1}$ ) in order to remove the template.

\section{3. $\mathrm{Fe}_{2} \mathrm{O}_{3} @ \mathrm{MCM}-41$ Sorbent Preparation}

Mesostructured $\mathrm{Fe}_{2} \mathrm{O}_{3} @ \mathrm{MCM}-41$ composite featuring $10 \%$ w/w of $\mathrm{Fe}_{2} \mathrm{O}_{3}$ (actual loading 9.9\% w/w) was prepared following the two-solvent incipient wetness impregnation. ${ }^{30}$ In detail, $0.2 \mathrm{~g}$ of MCM41_SM were dried at $150{ }^{\circ} \mathrm{C}$ for two days to remove the adsorbed water from the pores and dispersed in $12 \mathrm{ml}$ of hexane by stirring at $300 \mathrm{rpm}$ at room temperature. After 2 hours of stirring, $177.8 \mu \mathrm{l}$ (volume determined considering the total pore volume of the bare silica) of iron nitrate aqueous solution $(1.551 \mathrm{M})$ were added dropwise and the suspension was kept under stirring for further 2 hours. Then, the temperature was increased to $80{ }^{\circ} \mathrm{C}$ to evaporate the hexane and a wet orange powder was obtained. After drying at $80{ }^{\circ} \mathrm{C}$ overnight, the resulting sample was calcined at $500{ }^{\circ} \mathrm{C}$ for 2 hours (eating rate $2{ }^{\circ} \mathrm{C} \mathrm{min}^{-1}$ ) to decompose the iron nitrate and obtain the corresponding iron oxide. The obtained sample was labelled Fe_MCM41_SM.

\subsection{Characterization}

Low-angle $\left(2 \theta=0.8^{\circ}-2.5^{\circ}\right)$ and wide-angle $\left(2 \theta=10^{\circ}-\right.$ $70^{\circ}$ ) X-ray diffraction patterns were recorded on a Seifert instrument with a $\theta-\theta$ geometry and a $\mathrm{Cu} \mathrm{K} \alpha$ anode. The lattice parameter was calculated by the equation $a_{0}=2 d_{100} / \sqrt{3}$. Textural analyses were carried out on a Micromeritics 2020 system by determining the nitrogen adsorption-desorption isotherm at $-196{ }^{\circ} \mathrm{C}$. Prior to analyses, the samples were heated for 24 hours under vacuum at $250{ }^{\circ} \mathrm{C}$ (heating rate, $1{ }^{\circ} \mathrm{C} \cdot \mathrm{min}^{-1}$ ).

The Brunauer-Emmett-Teller (BET) specific surface area was calculated from the adsorption data in the $P / P_{0}$ range $0.05-0.17$. The total pore volume was calculated at $P / P_{0}=0.99$, while the pore size distribution (PSD) was determined by applying the density functional theory (DFT) model ( $\mathrm{N}_{2}$-cylidrical pores-oxide surface) using the isotherm adsorption branch. The wall thickness was calculated as the difference between the lattice parameter $\left(a_{0}\right)$ and the pore diameter $\left(D_{\text {pore }}\right)$.

Transmission electron microscopy (TEM) images were obtained by means of JEOL200CX microscope operating at an accelerating voltage of $160 \mathrm{kV}$. Finely ground samples were dispersed in ethanol and sonicated, the suspensions were then dropped on carbon-coated copper grids. Particle size distribution was obtained by manual counting of the minor and major diameter of each particles using Image J software. 
Dynamic Light Scattering (DLS) measurements were conducted by a Malvern Instrument Zeta Zetasized Ver 7.03, equipped with a $\mathrm{He}-\mathrm{Ne} \operatorname{laser}(\lambda=663 \mathrm{~nm}$, $\max$ $5 \mathrm{~mW}$ ) and operating at a scattering angle of $173^{\circ}$. For these analyses, $2 \mathrm{mg}$ of silica particles were dispersed in $2 \mathrm{~mL}$ of water and sonicated for 2 minutes. The dispersion was then transferred in a plastic cuvette and analyzed.

Room temperature (RT) ${ }^{57} \mathrm{Fe}$ Mössbauer spectra were measured in the transmission mode with ${ }^{57} \mathrm{Co}$ diffused into a $\mathrm{Rh}$ matrix as the source moving with constant acceleration. The spectrometer (Wissel) was calibrated by means of a standard $\alpha$-Fe foil and the isomer shift was expressed with respect to this standard at room temperature. The fitting of the spectra was performed with the help of the NORMOS program using Lorentzian profiles.

\subsection{Sulfidation and Regeneration Activity}

To determine sulfidation and regeneration activity, $50 \mathrm{mg}$ of iron oxide composite (Fe_MCM41_SM) were placed on a quartz wool bed $(50 \mathrm{mg})$ and then in a vertical quartz tubular reactor coaxially located in an electrical furnace. Before sulfidation, a pre-treatment at $300{ }^{\circ} \mathrm{C}$ for $30 \mathrm{~min}$ under helium flow was performed to remove air and moisture from the sorbent and the reactor. Then, a reactant gas containing $15200 \mathrm{ppm}$ of $\mathrm{H}_{2} \mathrm{~S}$ in helium (inlet flow, $20 \mathrm{~cm}^{3} \mathrm{~min}^{-1}$ ) was fed to the reactor and the $\mathrm{H}_{2} \mathrm{~S}$ content in the outlet flow during the sorption test was monitored by a quadrupole mass spectrometer (Thermo Electron Corporation). At the same time, $\mathrm{H}_{2} \mathrm{O}$ and $\mathrm{SO}_{2}$ signals were also monitored. Mass spectrometer calibration was carried out by recording the value of the electric signal of the $\mathrm{H}_{2} \mathrm{~S}$ species at different concentration, using gas cylinders of known $\mathrm{H}_{2} \mathrm{~S}$ concentration (100 ppm, 1000 ppm, $15200 \mathrm{ppm})$. Moreover, the less concentrated mixtures were diluted with $\mathrm{He}$ for obtaining calibration points from 33 to $104 \mathrm{ppm}$, i.e., lower or close to the breakthrough value $(100 \mathrm{ppm})$. After fitting with the Weighted Function, the electric signal values were plotted as function of $\mathrm{H}_{2} \mathrm{~S}$ concentration. A linear correlation between the $\mathrm{H}_{2} \mathrm{~S}$ signal $(\mathrm{eV})$ and the $\mathrm{H}_{2} \mathrm{~S}$ concentration (ppm) $(R=0.99987)$ was obtained. Standard deviation at $100 \mathrm{ppm}$ was estimated to be $5 \mathrm{ppm}$.

Once reached $15200 \mathrm{ppm}$, the measure was stopped and the system was purged by flowing helium $\left(20 \mathrm{~cm}^{3} \mathrm{~min}^{-1}\right)$ for 1 hour. The amount of sulfur retained per unit mass of sorbent was determined when the outlet $\mathrm{H}_{2} \mathrm{~S}$ concentration attained $100 \mathrm{ppm}$ by applying the formula:

$$
\text { sulfur retention capacity }(\mathrm{SRC})=\frac{\left(F_{s} * B_{t}\right)}{W}
$$

where $F_{s}$ is the mass flow rate of sulfur (mg of $\mathrm{S} \mathrm{s}^{-1}$ ), $B_{t}$ is the breakthrough time (s) and $W$ is the sorbent weight $(\mathrm{g})$, referring to the composite. The sulfur retention capacity of the sorbent was obtained as the difference between the $B_{t}$ value of the composite and the $B_{t}$ value of the bare silica support. The error on the SRC values was estimated to be $2 \mathrm{mg}_{\mathrm{s}} \mathrm{g}_{\text {sorbent }}^{-1}$ by carrying out several sulfidation cycles on fresh portions of the commercial sorbent Katalko $_{J M}$ 32-5. The regeneration process was performed on a Thermoquest $1100 \mathrm{TPD} / \mathrm{R} / \mathrm{O}$ apparatus equipped with a thermal conductivity detector (TCD) and a quadrupole mass spectrometer (QMS) for monitoring $\mathrm{SO}_{2}$ and $\mathrm{O}_{2}$ signals. The composite was heated under air flow $\left(20 \mathrm{~cm}^{3} \mathrm{~min}^{-1}\right)$ up to $500{ }^{\circ} \mathrm{C}$ (heating rate, $10{ }^{\circ} \mathrm{C} \mathrm{min}{ }^{-1}$ ) and the temperature was kept constant for 3 hours. To identify the sample after different sulfidation or regeneration runs, a letter ( $\mathrm{S}$ or $\mathrm{R}$, respectively) and a number (denoting successive runs) were added in the sample name.

\section{RESULTS AND DISCUSSION}

\subsection{Fresh Sorbent Characterization}

Figure 1(a) depicts low-angle XRD patterns of bare submicrosized MCM-41 (MCM41_SM) silica and corresponding composite (Fe_MCM41_SM). The presence of three reflections is clearly visible, ascribable to a hexagonal long-range mesoporous order (space group $P 6 \mathrm{~mm}$ ), proving that the impregnation route and the successive decomposition of the iron precursor have not given rise to any variation of the mesostructure. $d$-spacing and cell parameter $\left(a_{0}\right)$ were calculated using the most intense reflection (100) and reported in Table I.

$\mathrm{N}_{2}$ adsorption-desorption isotherms of the bare silica and the corresponding iron oxide composite are reported in Figure 1(b). According to IUPAC classification, both isotherms can be classify as IVB type ${ }^{31}$ with an evident capillary condensation in the range $0.2-0.3$. Textural parameters (surface area and pore volume), reported in Table I, highlight that the incorporation of the active phase has caused a decrease of about $16 \%$ and $22 \%$ in the surface area and pore volume values, respectively. DFT pore size distributions (Fig. 1(c)) point out that the symmetric distribution centred at $3.5 \mathrm{~nm}$ for MCM41_SM bare silica is shifted to lower values $(3.3 \mathrm{~nm})$ for the composite, due to the partial loading of the mesochannels by the iron oxide.

Wide-angle XRD patterns (Fig. 2(a)) reveal the presence in both the samples of a halo centred at $22^{\circ}$, related to amorphous silica, and two further weak and broad reflections at about $37^{\circ}$ and $62^{\circ}$, due to the iron species, which appear only in the composite, indirectly proving that the iron species is highly dispersed in the silica mesochannels. In order to verify the nature of the iron-bearing phase,

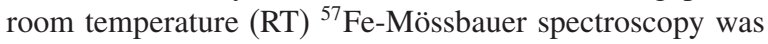
carried out (Fig. 2(b)). The spectrum shows a doublet with an isomer shift of $0.34 \pm 0.01 \mathrm{~mm} \mathrm{~s}^{-1}$, and a full width at half maximum (FWHM) of $0.47 \pm 0.01 \mathrm{~mm} \mathrm{~s}^{-1}$, indicating the formation of maghemite in form of ultrasmall nanoparticles. ${ }^{2,32-35}$ These values are very similar to those obtained in previous works for microsized $\gamma-\mathrm{Fe}_{2} \mathrm{O}_{3} @ \mathrm{MCM}-41 .^{25,26}$ 

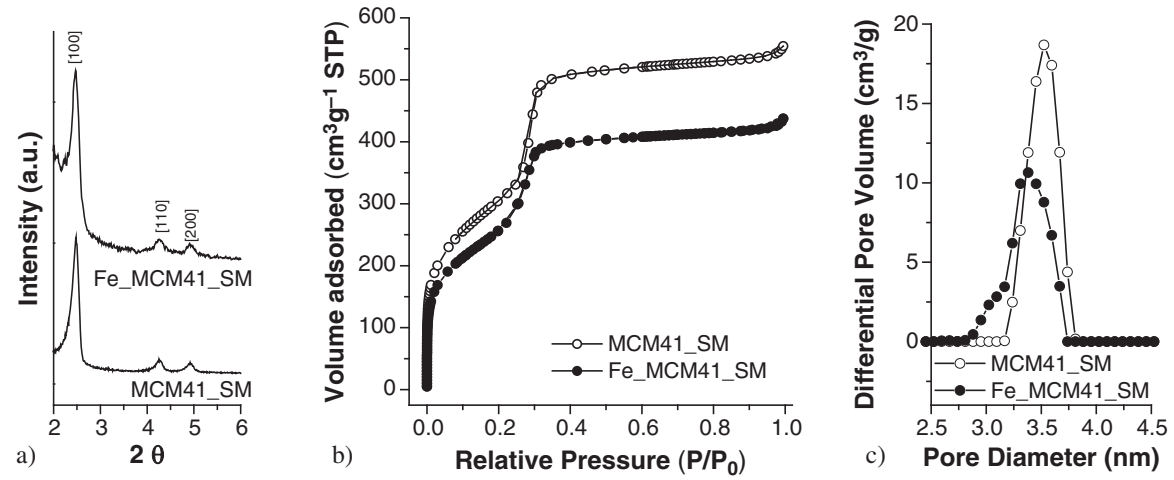

Figure 1. Low-angle XRD patterns (a) $\mathrm{N}_{2}$-physisorption isotherms (b) and pore size distributions (c) of the MCM41_SM bare silica and the corresponding Fe_MCM41_SM composite.

Representative TEM images of MCM41_SM (Figs. 3(a, b)) show that the sample consists of particles having mainly hexagonal shape (Fig. 3(a)), with an average dimension of about $600 \mathrm{~nm}(570 \pm 90 \mathrm{~nm})$. Moreover, the high magnification image (Fig. 3(b)) reveals the existence of well-defined ordered channels with dimension of about $2-3 \mathrm{~nm}$ in all the particles, confirming low-angle XRD and pore size distribution data. The morphology and texture of the particles were retained even after the impregnation and calcination steps (Figs. 3(c, d)). Moreover, the appearance of dark spots and dark channels, spread all over the silica particles, proves that the iron oxide active phase was homogeneously embedded into/over the silica particles, with no evidence of iron oxide microcrystal formation. High magnification TEM image (Fig. 3(d)) gives evidence that the iron oxide particles are highly dispersed inside the pores in form of ultrasmall nanoparticles (smaller than pore dimensions, see black arrows).

DLS measurements confirm the TEM data, being the hydrodynamic diameter and dispersity $(664 \pm 130 \mathrm{~nm})$ similar to the particle size and standard deviation determined from TEM $(570 \pm 90 \mathrm{~nm})$ (Fig. 3(a), inset).

Table I. Textural features obtained by $\mathrm{N}_{2}$-physisorption data for supports (MCM41_SM), composites (Fe_MCM41_SM, Fe_ MCM41_M) and three-time regenerated composites (Fe_MCM41_SM_3R, Fe_ MCM41_M_3R). $S_{\text {BET }}=$ Surface area; $V_{\mathrm{p}}=$ Pore volume; $D_{\mathrm{p}}=$ pore diameter; $w_{t}=$ walls thickness. Relative standard deviation: \%RSD $\left(S_{\mathrm{BET}}\right)=2.1 \% ; \% \operatorname{RSD}\left(V_{\mathrm{p}}\right)=1.1 \% ; \% \operatorname{RSD}\left(D_{\mathrm{p}}\right)=1.8 \% . d$-spacing $\left(d_{100}\right)$ and lattice parameter $\left(a_{0}\right)$ obtained from the X-ray diffraction data.

\begin{tabular}{lcccccc}
\hline Sample & $\begin{array}{c}S_{\mathrm{BET}} \\
\left(\mathrm{m}^{2} \mathrm{~g}^{-1}\right)\end{array}$ & $\begin{array}{c}V_{p} \\
\left(\mathrm{~cm}^{3} \mathrm{~g}^{-1}\right)\end{array}$ & $\begin{array}{c}D_{p} \\
(\mathrm{~nm})\end{array}$ & $\begin{array}{c}w_{t} \\
(\mathrm{~nm})\end{array}$ & $d_{100}$ & $a_{0}$ \\
\hline MCM41_SM & 1111 & 0.86 & 3.5 & 0.6 & 3.6 & 4.1 \\
Fe_MCM41_SM & 927 & 0.67 & 3.3 & 0.8 & 3.6 & 4.1 \\
Fe_MCM41_SM_3R & 756 & 0.53 & 3.3 & 0.8 & 3.6 & 4.1 \\
Fe_MCM41_M* & 768 & 0.53 & 3.2 & 0.8 & 3.5 & 4.0 \\
Fe_MCM41_M_3R* & 771 & 0.49 & 3.1 & 0.8 & 3.4 & 3.9 \\
\hline
\end{tabular}

Note: ${ }^{*}$ Textural values reported in the referenced articles. ${ }^{26}$
TEM allows to verify the role of ethyl acetate in regulating size and shape of the support's particles. In fact, the MCM41_M sample, prepared in the same conditions of MCM41_SM, but in the absence of ethyl acetate, shows mesostructured micrometric particles with irregular shape and very broad particle size distribution (Figs. 3(e, f)) The limited growth of the particle size and the shape regulation observed upon addition of ethyl acetate in the aqueous reaction mixture can be most probably ascribed to a decrease in the $\mathrm{pH}$, due to the formation of acetic acid. $^{26,36}$ The effect of ethyl acetate, already demonstrated for mesostructured silica in form of nanoparticles $(70-200 \mathrm{~nm}),{ }^{26,36}$ has been proven here also for submicrometric ones.

\subsection{Sulfidation and Regeneration Processes}

To evaluate the $\mathrm{H}_{2} \mathrm{~S}$ removal performance of the Fe_MCM41_SM composite, three sulfidation runs have been carried out at mid-temperature $\left(300{ }^{\circ} \mathrm{C}\right)$. After each sulfidation, a regeneration step has been performed by heating the sample under air flow up to $500{ }^{\circ} \mathrm{C}$, in order
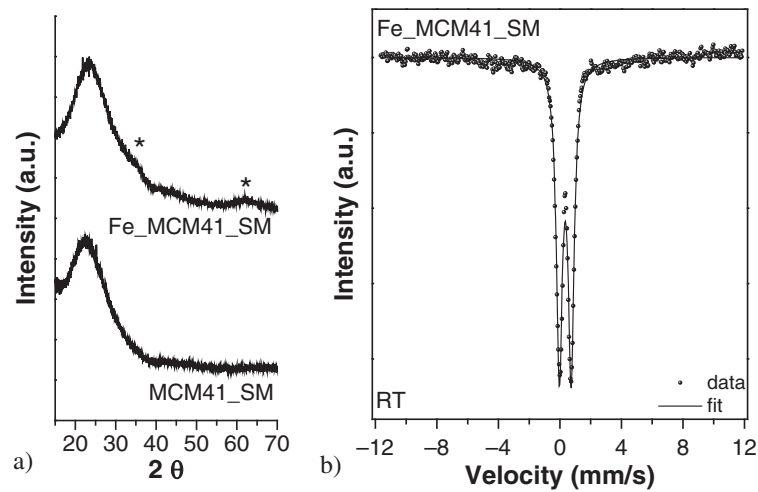

Figure 2. Wide-angle XRD patterns of MCM41_SM pure silica and corresponding Fe_MCM41_SM composite featuring 10\% w/w of

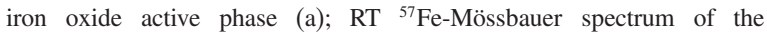
Fe_MCM41_SM composite (b). 

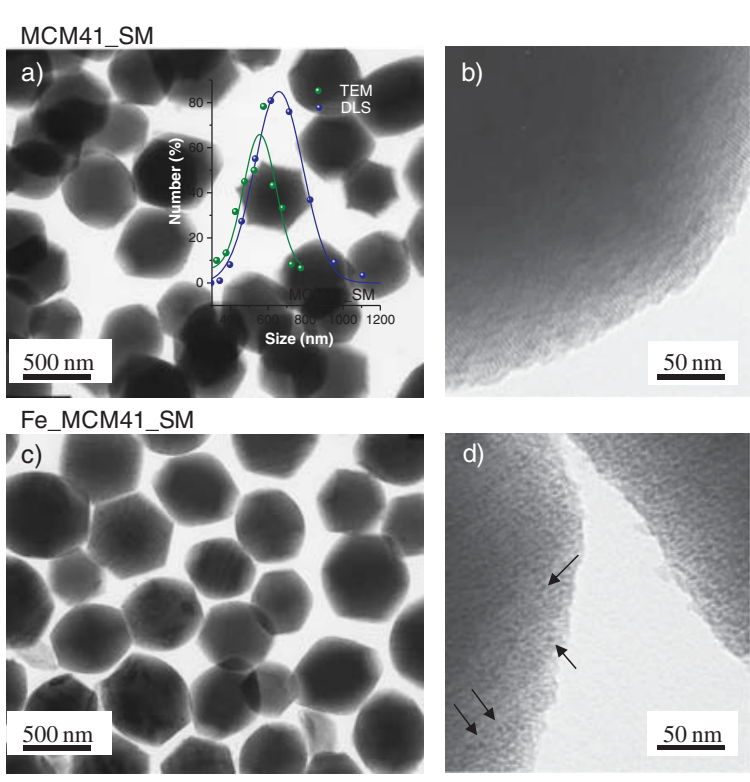

MCM41_M
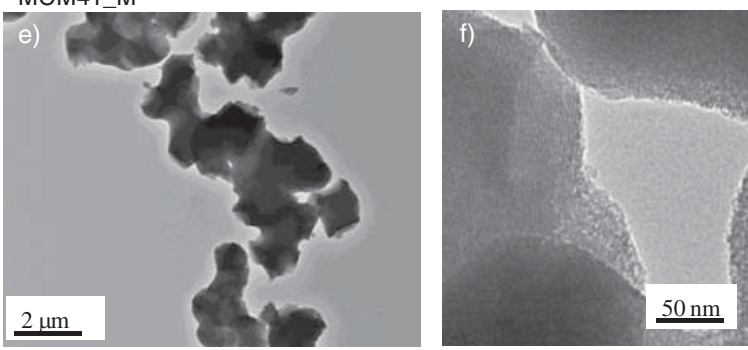

Figure 3. Bright field images at different magnification of MCM41_SM (a, b), and corresponding Fe_MCM41_SM composite (c, d). Inset in (a) shows the particles size distribution of MCM41_SM, determined by both dynamic light scattering and TEM images. Bright field images of the microsized MCM41_M support are also reported for comparison (e, f).

to regenerate the iron oxide phase. The sulfur retention capacities (SRC) for each sulfidation run have been listed in Table II and compared with the ones obtained for Fe_MCM41_M composite, built up with micrometric silica particles, and with those obtained for a commercial non-supported $\mathrm{ZnO}$ sorbent $\left(\mathrm{Katalko}_{\mathrm{JM}}\right.$ 32-5). Fe_MCM41_SM shows fairly lower SRC values compared with Fe_MCM41_M, but higher values than Katalko ${ }_{J M}$ 32-5 after the first sulfidation-regeneration cycle.

Figure 4(a) reports the $\mathrm{H}_{2} \mathrm{~S}$ profiles during the three sulfidation runs of the Fe_MCM41_SM sorbent, in which it is possible to evince the breakthrough time at $100 \mathrm{ppm}$ of $\mathrm{H}_{2} \mathrm{~S}$, used to determine the corresponding SRC values. The obtained values result to be very similar for the three sulfidation runs, with no evidence of decline after the regeneration steps. However, it should be noted from Figure 4(a) that, for run times beyond the breakthrough one, the profiles of $\mathrm{H}_{2} \mathrm{~S}$ released during the first and the successive sulfidation tests are very different, a much steeper increase being observed for the latter. Therefore, moving the $\mathrm{H}_{2} \mathrm{~S}$ limit concentration from $100 \mathrm{ppm}$ to, e.g., $400 \mathrm{ppm}$, a clear enhancement of the performance of the fresh sorbent is observable $\left(\mathrm{SRC}=30 \mathrm{mg}_{\mathrm{S}} \mathrm{g}_{\text {sorbent }}^{-1}\right)$, in comparison with that of the regenerated ones, which show a SRC value of $17 \pm 1 \mathrm{mg}_{\mathrm{S}} \mathrm{g}_{\text {sorbent }}^{-1}$

To verify the possible reactions involved during the sulfidation process, the release of different species, such as $\mathrm{H}_{2} \mathrm{O}$ and $\mathrm{SO}_{2}$ were also monitored, and the corresponding profiles during the first sulfidation run are reported in Figure 4(b) together with that of $\mathrm{H}_{2} \mathrm{~S}$. It can be observed from the figure that the retention of $\mathrm{H}_{2} \mathrm{~S}$ is accompanied by a significant release of $\mathrm{H}_{2} \mathrm{O}$ and by a very small amount of $\mathrm{SO}_{2}$. Considering these results, it can be suggested that the sulfidation process is largely governed by a substitution reaction, according to the Eqs. (1)-(3), ${ }^{25,26}$ though the oxidation-reduction reaction between $\mathrm{Fe}^{\mathrm{III}}$ and $\mathrm{H}_{2} \mathrm{~S}$ cannot be completely neglected, as confirmed by $\mathrm{SO}_{2}$ formation (Eqs. (4)-(5)). ${ }^{25,26}$

$$
\begin{gathered}
\mathrm{Fe}_{2} \mathrm{O}_{3}+3 \mathrm{H}_{2} \mathrm{~S} \rightarrow \mathrm{Fe}_{2} \mathrm{~S}_{3}+3 \mathrm{H}_{2} \mathrm{O} \\
2 \mathrm{Fe}_{2} \mathrm{~S}_{3} \rightarrow \mathrm{FeS}_{2}+\mathrm{Fe}_{3} \mathrm{~S}_{4} \\
\mathrm{Fe}_{2} \mathrm{~S}_{3} \rightarrow \alpha \mathrm{FeS}_{2}+\beta \mathrm{FeS}_{x}+\gamma \mathrm{S} \\
3 \mathrm{Fe}_{2} \mathrm{O}_{3}+\mathrm{H}_{2} \mathrm{~S} \rightarrow 6 \mathrm{FeO}+\mathrm{SO}_{2}+\mathrm{H}_{2} \mathrm{O} \\
\mathrm{FeO}+\mathrm{H}_{2} \mathrm{~S} \rightarrow \mathrm{FeS}+\mathrm{H}_{2} \mathrm{O}
\end{gathered}
$$

The regeneration process has been monitored following the composition of the gas released by both a Thermal Conductivity Detector (TCD) and a Quadrupole mass spectrometer (Fig. 4(c)). TCD profile (green line in the graph) shows the presence of two peaks centred at $255^{\circ} \mathrm{C}$ and $302{ }^{\circ} \mathrm{C}$, both ascribable to oxygen consumption, as confirmed by the QMS signals of $\mathrm{O}_{2}$ (orange line). Moreover, an additional large band associated with $\mathrm{SO}_{2}$ release has also been detected, as confirmed by the QMS signals of $\mathrm{SO}_{2}$ (black line). Considering the whole regeneration profile, the oxygen consumption can be relatedto the presence

Table II. Breakthrough time $\left(B_{t}\right)$ and sulfur retention capacity (SRC) of fresh and regenerated iron oxide-based sorbents (Fe_MCM41_SM, Fe_MCM41_M) and unsupported sorbent (Katalko $\left.{ }_{J M} 32-5\right)$. R1 is referred to the regenerated sample after one sulfidation and consecutive

\begin{tabular}{|c|c|c|c|}
\hline Sample & Sulfidation run & $B_{t}(\mathrm{~s})$ & $\operatorname{SRC}\left(\mathrm{mg}_{\mathrm{s}} \mathrm{g}_{\text {sorbent }}^{-1}\right)$ \\
\hline Fe_MCM41_SM & $1 \mathrm{st}$ & 98 & 13 \\
\hline Fe_MCM41_SM_R1 & 2nd & 107 & 14 \\
\hline Fe_MCM41_SM_R2 & $3 \mathrm{rd}$ & 99 & 13 \\
\hline Fe_MCM41_M* & $1 \mathrm{st}$ & 295 & 38 \\
\hline Fe_MCM41_M_R1 & 2 nd & 169 & 22 \\
\hline Fe_MCM41_M_R2 & $3 \mathrm{rd}$ & 169 & 22 \\
\hline Katalko $_{\text {JM }} 32-5^{*}$ & $1 \mathrm{st}$ & 122 & 16 \\
\hline Katalko $_{\text {JM }}$ 32-5_R1 & $2 \mathrm{nd}$ & 10 & 1 \\
\hline Katalko $_{\text {JM }}$ 32-5_R2 & $3 \mathrm{rd}$ & 13 & 2 \\
\hline
\end{tabular}
regeneration, R2 to the regenerated sample after two sulfidationregeneration cycles, R3 to the regenerated sample after three sulfidationregeneration cycles. The error in the SRC value is estimated to be $\pm 2 \mathrm{mg}_{\mathrm{S}} \mathrm{g}_{\text {sorbent }}^{-1}$.

Note: ${ }^{*}$ SRC value present in the referenced article. ${ }^{26}$ 

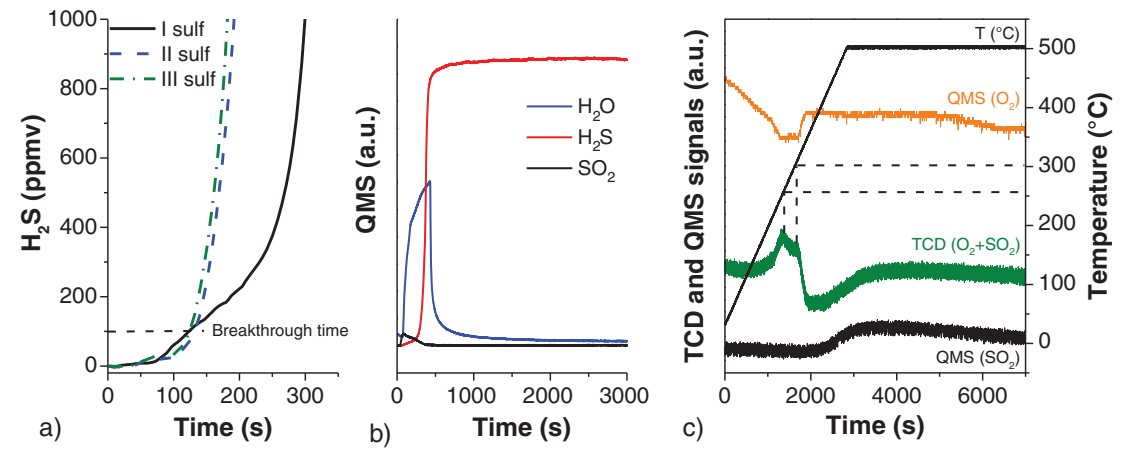

Figure 4. $\mathrm{H}_{2} \mathrm{~S}$ profiles during the sulfidation processes (sulf: Sulfidation) (a); $\mathrm{H}_{2} \mathrm{~S}, \mathrm{SO}_{2}$ and $\mathrm{H}_{2} \mathrm{O}$ breakthrough curves of the Fe_MCM41_SM during the first sulfidation run (b); TCD profile and $\mathrm{SO}_{2}$ and $\mathrm{O}_{2}$ Quadrupole Mass Spectrometer (QMS) signals of Fe_MCM41_SM during the first regeneration run.

of a sulfided iron phase, from which the iron oxide phase is restored by reaction with oxygen and consequent release of $\mathrm{SO}_{2}$.

\subsection{Regenerated Sorbent Characterization}

After three sulfidation-regeneration cycles, the submicrosized sorbent (Fe_MCM41_SM_3R) has been characterized by low-angle XRD and $\mathrm{N}_{2}$-physisorption measurements (Figs. 5(a-c)) to verify the porous structure stability, compared to the fresh (Fe_MCM41_SM) and the microsized ones (Fe_MCM41_M and Fe_MCM41_M_3R). The mesostructure is retained, as confirmed by the presence of well-defined reflections in the low-angle XRD pattern of Fe_MCM41_SM_3R.
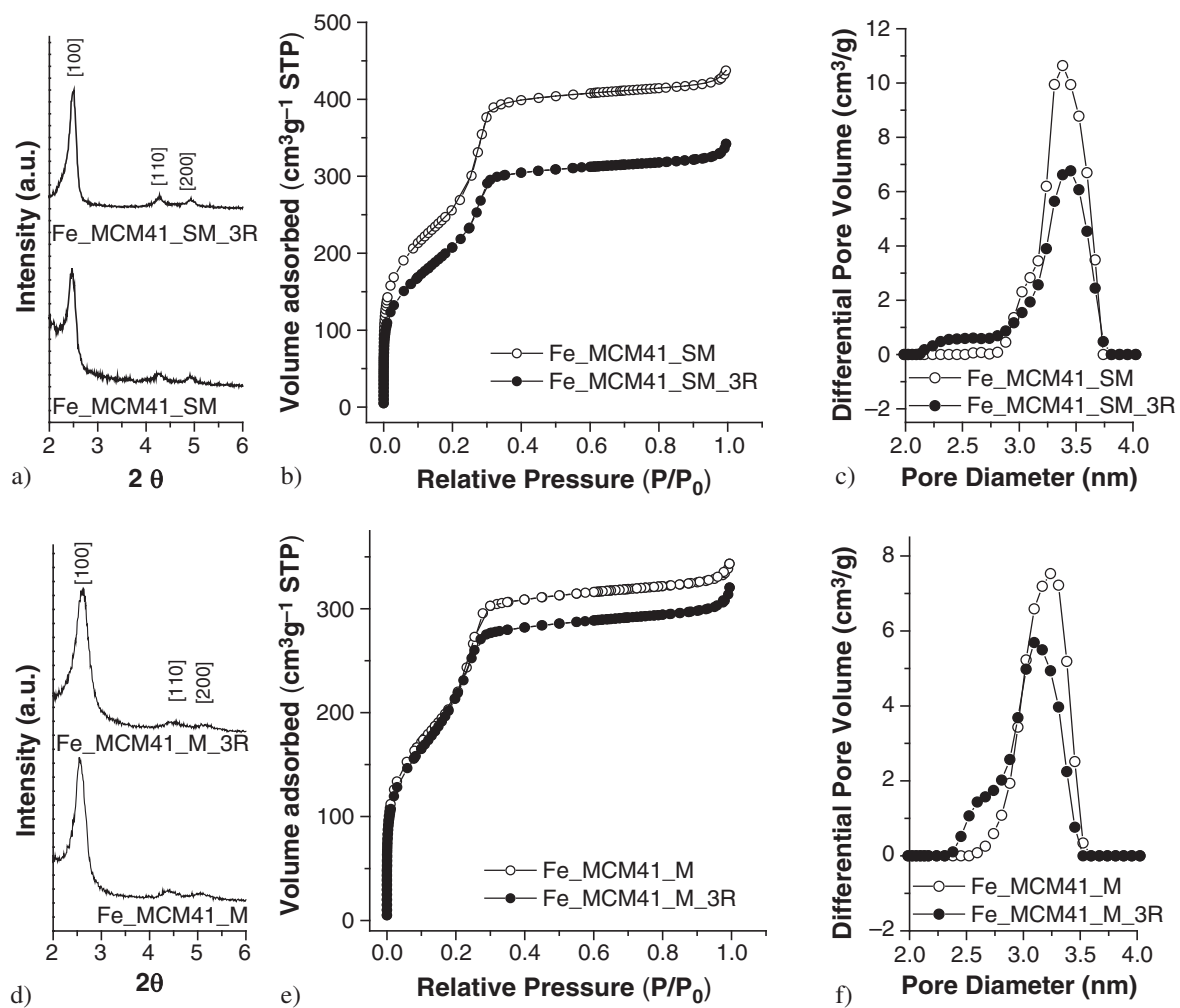

Figure 5. Low-angle XRD patterns, $\mathrm{N}_{2}$-physisorption isotherms and DFT pore size distributions of: Fresh Fe_MCM41_SM, and corresponding three-time sulfidated-regenerated Fe_MCM41_SM_3R composite (a-c); fresh Fe_MCM41_M and corresponding three-time sulfidatedregenerated Fe_MCM41_M_3R composite (d-f). (d) and (e) Reproduced with permission from [26], C. Cara, et al., J. Mater. Chem. A 5, 41 (2017). 
$\mathrm{N}_{2}$ adsorption-desorption isotherms give a similar information, even though a gradual reduction in the surface area (from 927 to $756 \mathrm{~m}^{2} \mathrm{~g}^{-1}$, almost $18 \%$ less) and pore volume (from 0.67 to $0.53 \mathrm{~cm}^{3} \mathrm{~g}^{-1}$ ) is evidenced (see Table I). DFT analysis reveals the appearance of a new contribution at lower pore size values in the PSD curve of the Fe_MCM41_SM_3R sample (Fig. 5(c)), indicating that the repeated sulfidation-regeneration cycles cause a reduction in the diameter of a portion of mesopores. The retention of the porous structure (Fig. 5(d)) as well as the presence of the contribution at lower pore size values (Fig. 5(f)) can also be observed for the analogous Fe_MCM41_M_3R with micrometric size. However, at variance with Fe_MCM41_SM_3R, surface area and pore volume of the micrometric composite result unchanged after the sulfidation-regeneration cycles (see Table I).

According to the literature, the collapse of the porous structure in mesostructured silica systems can be related to the hydrolysis of siloxane bridges at the surface to form silanol groups. ${ }^{37}$ Taking into account the role of ethyl acetate as growth inhibitor and shape regulator, the differences in the structural stability of Fe_MCM41_SM and Fe_MCM41_M could be reasonably ascribed to its effect on the concentration and nature of the surface silanol groups. A partial collapse of the pore structure has been also revealed, even more pronounced, for nanosized MCM-41 particles, synthesized using a higher amounts of ethyl acetate. ${ }^{25,38}$ As a consequence, a gradual covering of a portion of the active phase takes place, hampering the reaction of such iron oxide nanoparticles with $\mathrm{H}_{2} \mathrm{~S}$, affecting the $\mathrm{H}_{2} \mathrm{~S}$ removal performance in the successive cycles. Therefore, the reduction in the size of the mesostructured support particles from micrometric (Fe_MCM41_M) to sub-micrometric (Fe_MCM41_SM) does not cause the expected enhancement in terms of sulfur retention capacity; on the contrary, a partial decline of the SRC performances was observed. Excluding the differences between the two composites in the first sulfidation, due to the possible occurrence of other phenomena, (such as adsorbed water, no complete crystallization of the active phase, stabilization of the porous structure in the test conditions) $)^{25}$ the comparison of the SRC values in the successive sulfidation cycles highlights that the high stability of the porous structure of the microsized composite plays a key role in guaranteeing high $\mathrm{H}_{2} \mathrm{~S}$ removal performances (67\% higher than for the sub-microsized one). Therefore, the present results, while confirming the remarkable size and shaperegulating effect of ethyl acetate, clearly show its detrimental influence on the porous structure stability and the performance of the related sorbent.

\section{CONCLUSION}

$\gamma-\mathrm{Fe}_{2} \mathrm{O}_{3} @ \mathrm{MCM}-41$ composites have already been proved to be promising sorbents for $\mathrm{H}_{2} \mathrm{~S}$ adsorption in the midtemperature range. Furthermore, it was demonstrated that the dimension of the silica particles used as support plays a strategic role in the performance of the sorbent: while micrometric silica particles obtained in the absence of a regulating agent (ethyl acetate) are highly stable over the repeated sulfidation-regeneration cycles, a partial collapse of the silica structure occurred in the case of nanometric ones, causing detrimental effects on $\mathrm{H}_{2} \mathrm{~S}$ removal performances. Here, with the ambition of joining the high accessibility to the iron oxide active phase embedded in silica nanoparticles, owing to its short pore channels, with the high thermal stability of the pore structure shown by the micrometric systems, sub-micrometric silica particles were synthesized and employed to homogeneously disperse $\gamma$ - $\mathrm{Fe}_{2} \mathrm{O}_{3}$ ultrasmall nanoparticles. The $\mathrm{H}_{2} \mathrm{~S}$ removal performances of the resulting sorbent (Fe_MCM41_SM) over three repeated sulfidation cycles were then compared with those of the micrometric sample (Fe_MCM41_M). Even though the $\mathrm{H}_{2} \mathrm{~S}$ removal capacities of $\mathrm{Fe} \_$MCM41_SM are stable and much higher than those of the commercial sorbent after the first sulfidation, they are lower than those of the micrometric Fe_MCM41_M. The textural characterization of the sorbents after the repeated cycles reveals that the reduction of the silica particle dimension causes a detrimental effect on the $\mathrm{H}_{2} \mathrm{~S}$ removal performances, due to the partial collapse of the structure. However, in the light of the similar $\mathrm{H}_{2} \mathrm{~S}$ profiles of Fe_MCM41_SM after the first sulfidation, it seems that the porous structure of the regenerated sorbent remains stable, enabling a steady performance over the course of different sulfidation processes.

Acknowledgments: Consorzio AUSI (Consorzio per la promozione delle Attivita Universitarie del SulcisIglesiente) is gratefully acknowledged for the grant financing for Claudio Cara and Andrea Ardu. PON-RI_Ricerca Innovatizione 2014-2020 is acknowledged for the grant financing for Mirko Antonio Vacca. This work was also supported by the Fondazione Banco di Sardegna, Progetti biennali RAS/FdS (F72F16003070002), Title: Smart Nano-structured Functional Materials: Synthesis and Characterization with Focus on the Specific Interactions between Solid Surfaces and Biomacromolecules. We deeply appreciate Professor Daniel Niznansky for the helpful discussion on Mössabuer spectroscopy data.

\section{References and Notes}

1. A. Hervault and N. T. K. Thanh, Nanoscale 6, 20 (2014).

2. R. M. Cornell and U. Schwertmann, The Iron Oxides, FRG: WileyVCH Verlag GmbH \& Co. KGaA, Weinheim (2003).

3. K. Sivula, F. Le Formal, and M. Grätzel, ChemSusChem. 4, 4 (2011).

4. M. C. Pereira, L. C. A. Oliveira, and E. Murad, Clay Miner 47, 3 (2012).

5. Q. Hao, L. Li, X. Yin, S. Liu, Q. Li, and T. Wang, Mater. Sci. Eng. B Solid-State Mater. Adv. Technol. 176, 7 (2011).

6. H. Chen, Y. Zhao, M. Yang, J. He, P. K. Chu, J. Zhang, and S. Wu, Anal. Chim. Acta 659, 1 (2010).

7. A. K. Dutta, S. K. Maji, and B. Adhikary, Mater. Res. Bull. 49, 1 (2014). 
8. M. B. Gawande, P. S. Branco, and R. S. Varma, Chem. Soc. Rev. 42, 8 (2013).

9. N. Nasongkla, E. Bey, J. Ren, H. Ai, C. Khemtong, J. S. Guthi, S.-F. Chin, A. D. Sherry, D. A. Boothman, and J. Gao, Nano Lett. 6, 11 (2006).

10. M. Arruebo, R. Fernández-Pacheco, M. R. Ibarra, and J. Santamaría, Nano Today 2, 3 (2007).

11. V. Mameli, A. Musinu, A. Ardu, G. Ennas, D. Peddis, D. Niznansky, C. Sangregorio, C. Innocenti, N. T. K. Thanh, and C. Cannas, Nanoscale 8, 19 (2016).

12. A. K. Gupta and M. Gupta, Biomaterials 26, 18 (2005).

13. C. S. S. R. Kumar and F. Mohammad, Adv. Drug Deliv. Rev. 63, 9 (2011).

14. K. Movlaee, M. Ganjali, P. Norouzi, and G. Neri, Nanomaterials 7, 12 (2017).

15. F. G. de Souza, J. A. Marins, J. C. Pinto, G. E. de Oliveira, C. M. Rodrigues, and L. M. T. R. Lima, J. Mater. Sci. 45, 18 (2010).

16. X. Peng, Y. Zhao, T. Yang, Y. Yang, Y. Jiang, Z. Ma, X. Li, J. Hou, B. Xi, and H. Liu, Microporous Mesoporous Mater. 258, 26 (2018).

17. P. N. Dave and L. V. Chopda, J. Nanotechnol. 2014, 1 (2014).

18. G. Huang, E. He, Z. Wang, H. Fan, J. Shangguan, E. Croiset, and Z. Chen, Ind. Eng. Chem. Res. 54, 34 (2015).

19. M. Wu, L. Shi, T. T. Lim, A. Veksha, F. Yu, H. Fan, and J. Mi, Chem. Eng. J. 353, 273 (2018).

20. M. Wu, T. Li, H. Li, H. Fan, and J. Mi, Energy and Fuels 31, 12 (2017).

21. M. Wu, L. Jia, H. Fan, and J. Mi, Energy Fuels 31, 9 (2017).

22. M. Mureddu, I. Ferino, E. Rombi, M. G. Cutrufello, P. Deiana, A. Ardu, A. Musinu, G. Piccaluga, and C. Cannas, Fuel 102, 691 (2012).

23. B. Elyassi, Y. Al Wahedi, N. Rajabbeigi, P. Kumar, J. S. Jeong, X. Zhang, P. Kumar, V. V Balasubramanian, M. S. Katsiotis, K. Andre Mkhoyan, N. Boukos, S. Al Hashimi, and M. Tsapatsis, Microporous Mesoporous Mater. 190, 152 (2014).
24. M. Behl, J. Yeom, Q. Lineberry, P. K. Jain, and M. A. Shannon, Nat. Nanotechnol. 7, 12 (2012).

25. C. Cara, E. Rombi, V. Mameli, A. Ardu, M. S. Angotzi, D. Niznansky, A. Musinu, and C. Cannas, J. Phys. Chem. C 122, 23 (2018).

26. C. Cara, E. Rombi, A. Musinu, V. Mameli, A. Ardu, M. S. Angotzi, L. Atzori, D. Niznansky, H. L. Xin, and C. Cannas, J. Mater. Chem. A 5, 41 (2017).

27. M. S. Shah, M. Tsapatsis, and J. I. Siepmann, Chem. Rev. 117, 14 (2017).

28. M. Mureddu, I. Ferino, A. Musinu, A. Ardu, E. Rombi, M. G. Cutrufello, P. Deiana, M. Fantauzzi, and C. Cannas, J. Mater. Chem. A 2, 45 (2014).

29. S. C. Tseng, S. S. Tamhankar, and C. Y. Wen, Chem. Eng. Sci. 36, 8 (1981).

30. J. Van Der Meer, I. Bardez-Giboire, C. Mercier, B. Revel, A. Davidson, and R. Denoyel, J. Phy. Chem. C 114, 8 (2010).

31. M. Thommes, K. Kaneko, A. V. Neimark, J. P. Olivier, F. RodriguezReinoso, J. Rouquerol, and K. S. W. Sing, Pure Appl. Chem. 87, 9 (2015).

32. F. Bødker, M. F. Hansen, and C. B. Koch, Matter Mater. Phys. 61,10 (2000).

33. F. Bødker and S. Mørup, Europhys. Lett. 52, 2 (2000).

34. G. Muscas, G. Concas, C. Cannas, A. Musinu, A. Ardu, F. Orrù, D. Fiorani, S. Laureti, D. Rinaldi, G. Piccaluga, and D. Peddis, J. Phys. Chem. C 117, 44 (2013).

35. V. Mameli, A. Musinu, D. Niznansky, D. Peddis, G. Ennas, A. Ardu, C. Lugliè, and C. Cannas, J. Phys. Chem. C 120, 48 (2016).

36. T. Suteewong, H. Sai, R. Cohen, S. Wang, M. Bradbury, B. Baird, S. M. Gruner, and U. Wiesner, J. Am. Chem. Soc. 133, 2 (2011).

37. M. Varache, I. Bezverkhyy, F. Bouyer, R. Chassagnon, F. Baras, and F. Bouyer, J. Nanoparticle Res. 17, 9 (2015).

38. C. M. Carbonaro, F. Orrù, P. C. Ricci, A. Ardu, R. Corpino, D. Chiriu, F. Angius, A. Mura, and C. Cannas, Microporous Mesoporous Mater. 225, 432 (2016).

Received: 24 July 2018. Accepted: 15 September 2018. 